\title{
Ethos discursivo
}

\section{Maria da Glória Corrêa di Fanti ${ }^{1}$ Liz Feréz}

1 Pontifícia Universidade Católica do Rio Grande do Sul, Porto Alegre, Rio Grande do Sul, Brasil. 2 Université Paris VIII, Centre d'Études sur les Médias, les Technologies et I'Internalisation, Paris, França.

A noção de ethos discursivo tem sido objeto de reflexão de diferentes pesquisas que estudam a imagem do enunciador produzida no discurso. Essa imagem, conforme Maingueneau (2005, 2006, 2008, 2014), é construída no discurso em suas múltiplas relações com o outro (sujeitos e discursos) e emerge na articulação entre variados elementos (verbais e não verbais, éticos e estéticos etc.), os quais necessitam da incorporação do interlocutor para apreendê-la em um conjunto complexo de representações sociais e culturais. ${ }^{1}$

O ethos discursivo, embora se diferencie da tradição retórica, não deixa de concordar com três ideias básicas do ethos aristotélico: o ethos é (a) uma noção discursiva, isto é, constitui-se por meio do discurso, não sendo, portanto, uma "imagem do locutor exterior à fala", (b) um "processo interativo de influência sobre o outro" e (c) uma noção "[...] híbrida (sócio-discursiva), tem um comportamento socialmente avaliado, que não deve ser apreendido fora de uma situação de comunicação precisa", própria de uma conjuntura histórico-social (MAINGUENEAU, 2006, p. 60).

$\mathrm{Na}$ perspectiva discursiva, há em todo texto uma vocalidade que pode ser relacionada com a "caracterização do corpo do enunciador" construído no discurso (MAINGUENEAU, 2006, p.61). O ethos recobre não apenas a dimensão verbal, mas também um conjunto de características psíquicas e físicas que se associam a um fiador, o qual se revela por meio de um tom, atestando o que diz. O fiador, desse modo, recebe um caráter e uma corporalidade que variarão conforme a constituição dos textos, a cena de fala criada. Enquanto "o caráter corresponde a um feixe de traços psicológicos", a corporalidade está ligada a uma "compleição física e a uma forma de vestir" (MAINGUENEAU, 2006, p. 62).

\footnotetext{
${ }^{1}$ Parte das ideias sobre ethos foram desenvolvidas no artigo Identidade, alteridade e cultura regional: a construção do ethos milongueiro gaúcho (DI FANTI, 2009).
}

Além do caráter e da corporalidade, o ethos " [...] implica uma forma de mover-se no espaço social, uma disciplina tácita do corpo, apreendida por meio de um comportamento" (MAINGUENEAU, 2006, p.62). A incorporação do interlocutor, sob esse enfoque, não se dá pela simples identificação de uma personagem fiadora, mas sim pela implicação em "um mundo ético" que, segundo o analista do discurso, funciona como um conjunto difuso de representações sociais e culturais, o que evidencia uma tensão entre o ethos almejado e o efetivamente elaborado.

Amossy, ao tratar da questão de ethos e identidade verbal, observa que o locutor produz no discurso uma diversidade de imagens de si que revelam facetas da sua identidade. E essas características identitárias também podem projetar representações de grupos, em que o indivíduo singular emerge como "o representante de uma coletividade e em que o discurso pode aparecer como um conjunto de vozes inter-relacionadas" (AMOSSY, 2010, p. 211). Desse modo, a apresentação de si no discurso pode remeter tanto a grupos que ainda não tenham contornos claros como a grupos reconhecidos no espaço social, que queiram, por exemplo, ser reconhecidos identitariamente ou se afirmar via relações de poder.

A apresentação de si no discurso, que confere autoridade ao locutor, permite, em diferentes graus, por um lado, a emergência de afinidades e proximidades com determinados indivíduos assim como, por outro, a emergência de distinções e distanciamentos de outros. Compreender a imagem que se constrói no discurso, tanto individual como coletiva, de acordo com Amossy, implica reflexões sobre ethos prévio e ethos discursivo. Enquanto o primeiro supõe conhecimentos sobre o modo de ser do locutor, o segundo exige a observação do discurso por meio do qual o locutor projeta uma imagem de si e negocia sua identidade (AMOSSY, 2010, p.212). Para a autora, não há como dissociar uma 
instância da outra, já que o locutor no discurso refere-se a dados anteriores, ressignificando-os. Na negociação da construção da imagem de si, o locutor se engaja em um diálogo com o que os outros dizem e pensam sobre a sua pessoa.

O presente dossiê, ao abrir espaço para o debate sobre o alcance, desafios e potencialidades da noção de ethos discursivo, reúne, nesta edição da Letras de Hoje, um conjunto de artigos que focalizam o funcionamento da produção, circulação e recepção de diferentes discursos na sociedade. Abre este número o artigo de Dominique Maingueneau, que desenvolve uma reflexão crítica sobre a noção de ethos discursivo, considerando a sua contribuição, desde a década de 1980, para o desenvolvimento dessa problemática. Sua reflexão leva em conta a diversidade de manifestações do discurso, o processo de construção do ethos e a relação estreita entre dimensões verbais e icônicas. Para fundamentar suas ponderações, analisa sites da Internet e publicidades. Segue seu trabalho, o artigo de Maria Cecília Pérez Souzae-Silva e Décio Rocha, que discutem a inter-relação entre cenografia e ethos para Maingueneau.
Articulando reflexões teóricas e práticas, grande parte dos pesquisadores contemplam, em seus artigos, análises de discursos que circulam na Internet e/ou redes sociais, como é o caso de Juan Manuel López Muñoz e Tamiris Machado Gonçalves; Cristina Rothier Duarte e Francisco Vieira da Silva; Bianca Assis Oliveira de Paula, Fabio Sampaio de Almeida e Maria Cristina Giorgi; Eliane Davila dos Santos e Gislene Feiten Haubrich; e Ernani Cesar de Freitas e Luis Henrique Boaventura.

Análises de discursos veiculados em revistas são desenvolvidas por Luciana Salazar Salgado e Marina Delege; Elaine Cristina Fonseca; e Luana Ferreira de Souza. No campo cultural, são apresentadas reflexões por Hélène Barthelmebs-Raguin; e Lia Raquel Vieira de Andrade e Juliana Geórgia Gonçalves Araújo. Em âmbito de gravação telefônica, Welton Pereira e Silva trabalha com a questão do golpe de falso sequestro. A publicidade é contemplada por Silma Ramos Coimbra Mendes e Edgar Godoi Gabriel.

Agradecemos a importante colaboração dos autores deste número e convidamos a comunidade acadêmica a prestigiar as reflexões aqui desenvolvidas.

\section{Referências}

AMOSSY, R. (Org.). La présentation de soi. Ethos et identité verbale. Paris: PUF, 2010.

DI FANTI, M. G. C. Identidade, alteridade e cultura regional: a construção do ethos milongueiro gaúcho. Alfa: Revista de Linguística (UNESP. Online), v. 53, p. 149-166, 2009.

MAINGUENEAU, D. Retour critique sur l'éthos. Langage et société, v. 149, n. 3, p. 31-48, 2014.

MAINGUENEAU, D. A propósito do ethos. Tradução de Luciana Salgado. In: MOTTA, A. R.; SALGADO, L. (Org.). Ethos discursivo. São Paulo: Contexto, 2008.

MAINGUENEAU, D. Cenas da enunciação. Organizado por Sírio Possenti e Maria Cecília Pérez de Souzae-Silva e tradução de Sírio Possenti. Curitiba: Criar, 2006.

MAINGUENEAU, D. Ethos, cenografia, incorporação. In: AMOSSY, R. (Org.). Imagens de si no discurso: a construção do Ethos. Tradução de Dílson Ferreira da Cruz, Fabiano Comesu e Sírio Possenti. São Paulo: Contexto, 2005.

\section{Organizadoras}

(D) MARIA DA GLÓRIA CORRÊA DI FANTI < gloria.difanti@pucrs.br> Professora-pesquisadora da PUCRS e Bolsista PQ/CNPq.

(D) LIZ FERÉ <info@lizfere.com>

Professora-pesquisadora da Université Paris VIII/CEMTI. 